\title{
Планирование тренировочного процесса борцов вольного стиля высокой квалификации на основе анализа соревновательной деятельности
}

\author{
Колодезникова М.Г. ${ }^{*}$, Колодезников К.С., Сидоров П.И. \\ Северо-Восточный федеральный университет им. М.К. Аммосова \\ 2. Якутск, Россия \\ ORCID:oooo-ooo3-0327-1976, mgkolod@inbox.ru \\ ORCID:oooo-ooo3-3427-5056,kkirsan@mail.ru \\ ORCID:OOOo-ooo2-5143-3792,sportedin@mail.ru
}

\begin{abstract}
Аннотация: В данной работе представлено планирование тренировочного процесса борцов высокой квалификации на основе анализа соревновательной деятельности борцов высокой квалификации, членов сборной команды Республики Саха (Якутия). Современные тенденции развития вольной борьбы заставляют специалистов быть в непрерывном поиске целесообразных педагогических воздействий на спортсменов различной квалификации с целью создания оптимальной системы совершенствования различных сторон их подготовленности. Одним из основных направлений является разработка эффективной методики технико-тактической подготовки квалифицированных борцов, максимально адаптированной к требованиям изменившихся правил проведения борцовских поединков. Материалъ. Совершенствование планирования тренировочного процесса борцов вольного стиля, входящих в основной состав сборной команды Республики Саха (Якутия), на основе анализа соревновательной деятельности. Методъ исследования. Анализ научно-методической литературы; эмпирические методы: наблюдение, беседа, анализ видеозаписи соревновательных поединков; анализ соревновательной деятельности борцов высокой квалификации; методы математической статистики, графической обработки экспериментальных данных. Резулътатъљ. Проведено специальное исследование, направленное на решение практических проблем по совершенствованию учебнотренировочного процесса подготовки борцов вольного стиля. В экспериментальной работе изучены и проанализированы выступления ведущих борцов вольного стиля. Объектом наблюдения были соревнования по вольной борьбе: Чемпионат России 2016 г. (Якутск), Чемпионат России 2017 г. (Назрань), международный турнир Голден Гран-При им. И.С. Ярыгина 2016 г. (Красноярск). Просмотр выступления борцов вольного стиля на Чемпионате России 2016 г., Чемпионате России 2017 г. и на турнире И.С. Ярыгина позволяет сделать вывод, что каким бы ни был уровень технической подготовленности, каким бы эффективным приемов ни владел борец, без соответствующей тактической подготовки провести прием невозможно. На основе анализа соревновательной деятельности составлен тренировочный план подготовки борцов вольного стиля сборной Республики Саха (Якутия) на 2017 год. Заключение. Проведенное исследование доказало, что применение анализа соревновательной деятельности тренерами и спортсменами совершенствует спортивное мастерство и повышает результативность. Данный опыт можно рекомендовать для использования всем ведущим тренерам и спортсменам.

Ключевые слова: вольная борьба, соревновательная деятельность, анализ техникотактических действий, планирование тренировочного процесса, результативность, спортивные соревнования, квалифицированные спортсмены, спортивное мастерство.
\end{abstract}

Для цитирования: Колодезникова М.Г.*, Колодезников К.С., Сидоров П.И. Планирование тренировочного процесса борцов вольного стиля высокой квалификации на основе анализа соревновательной деятельности. Педагогико-психологические и медико-биологические проблемы физической культуры и спорта. 2020; 15(4): 5-12. DOI: 10.14526/2070-4798-2020-15-4-5-12

\section{Training process planning in highly-qualified freestyle wrestlers on the basis of competitive activity analysis}

\author{
Margarite G. Kolodeznikova*, Kirsan S. Kolodeznikov, Pavel I. Sidorov
}




\title{
M.K. Ammosov North-Eastern Federal University Yakutsk, Russia \\ ORCID:0ooo-ooo3-o327-1976, mgkolod@inbox.ru \\ ORCID:0ooo-ooo3-3427-5056, kkirsan@mail.ru \\ ORCID:oooo-ooo2-5143-3792,sportedin@mail.ru
}

\begin{abstract}
The work presents training process planning in highly-qualified wrestlers on the basis of competitive activity analysis of wrestlers, members of the Republic of Sakha (Yakutia) national team. Modern tendencies of freestyle wrestling development make the specialists search for reasonable pedagogical influences on athletes of different qualification in order to create an optimal system of different sides of their readiness improvement. One of the main directions is an effective methodology of technical-tactical training creation for qualified wrestlers. It is adapted to the demands of the changed rules of combats organization. Materials. The training process planning improvement in freestyle wrestlers. They form the first national team of the Republic of Sakha (Yakutia), on the basis of competitive activity analysis. Research methods. Information sources analysis; empirical methods: observation, conversation, video of competitive combats analysis; highly-qualified wrestlers' competitive activity analysis; methods of mathematical statistics, graphic treatment of the experimental results. Results. We held a special research directed toward practical problems solution. They concern educationaltraining process improvement in freestyle wrestlers. In the experimental work we studied and analyzed the performances of the leading freestyle wrestlers. The object of the research formed freestyle wrestling competitions: Championship of Russia 2016 (Yakutsk), Championship of Russia 2017 (Nazran), International tournament Golden Grand Prix named after I.S. Yarygin 2016 (Krasnoyarsk). Watching the performances of freestyle wrestlers at the Championship of Russia 2016, Championship of Russia 2017 and during the tournament named after I.S. Yarygin helps to come to the following conclusion: regardless of the level of technical readiness and the effectiveness of the wrestler's technique it is impossible to realize a technique without the corresponding tactical training. On the basis of competitive activity analysis we formed the training plan of training for freestyle wrestlers of the national team of the Republic of Sakha (Yakutia) for 2017. Conclusion. The held research proved that competitive activity analysis use by the coaches and athletes develops sportsmanship and increases the effectiveness of sports activity. The presented experience can be recommended for all leading coaches and athletes.

Keywords: freestyle wrestling, competitive activity, technical-tactical actions analysis, training process planning, effectiveness, sports competitions, qualified athletes, sportsmanship.
\end{abstract}

For citation: Margarite G. Kolodeznikova*, Kirsan S. Kolodeznikov, Pavel I. Sidorov. Training process planning in highly-qualified freestyle wrestlers on the basis of competitive activity analysis. Russian Journal of Physical Education and Sport. 2020; 15(4): 5-12. DOI: 10.14526/2070-4798-2020-15-4-5-12

\section{ВВЕДЕНИЕ}

Современные тенденции развития спортивной борьбы характеризуются частыми и далеко не всегда оправданными изменениями правил соревнований, а также постоянно возрастающей конкуренцией на международном ковре, включая Олимпийские игры, мировые и европейские чемпионаты[1]. Это заставляет специалистов быть в непрерывном поиске целесообразных педагогических воздействий на спортсменов различной квалификации с целью создания оптимальной системы совершенствования различных сторон их подготовленности. Одним из основных направлений является разработка эффективной методики технико-тактической подготовки квалифицированных борцов, максимально адаптированной к требованиям изменившихся правил проведения борцовских поединков[2].

Высокие и стабильные спортивные результаты борцов в значительной мере определяются качеством построения многолетнего учебно-тренировочного процесса. При этом под качеством учебнотренировочного плана, как правило, подразумевается рациональное распределение различных средств и методов тренировки во времени. Особую значимость имеет этап (макроцикл) подготовки к наиболее важным соревнованиям. Это обусловлено тем, что стратегические ошибки, допущенные при планировании предсоревновательной 
подготовки, непосредственно отразятся на уровне спортивных достижений[3,6,7,8,9].

На основании этого можно заключить, что в настоящее время возникла необходимость в проведении специального исследования, направленного на решение практических проблем по совершенствованию учебнотренировочного процесса подготовки борцов вольного стиля на основе анализа соревновательной деятельности.

В данной работе проанализирована соревновательная деятельность борцов высокой квалификации, членов сборной команды Республики Саха (Якутия), мастеров спорта Российской Федерации и мастеров спорта международного класса - Виктора Рассадина (Борец-1), Ньургуна Скрябина(Боре 2) и Егора Пономарева (Борец-3).

Цель исследования: совершенствование планирования тренировочного процесса и повышение результатов выступления на официальных соревнованиях на основе анализа соревновательной деятельности борцов вольного стиля, входящих в основной состав сборной команды Республики Саха (Якутия).

\section{МАТЕРИАЛЫ И МЕТОДЫ}

При проведении исследовательской работы нами были применены следующие методы: анализ научно-методической литературы; эмпирические методы: наблюдение, беседа, анализ видеозаписи соревновательных поединков; анализ соревновательной деятельности борцов высокой квалификации; методы математической статистики, графической обработки экспериментальных данных. Объектом наблюдения были соревнования по вольной борьбе: Чемпионат России 2016 г. (Якутск), Чемпионат России 2017 г. (Назрань), международный турнир Голден ГранПри им. И.С. Ярыгина 2016 г. (Красноярск). Нами были проанализированы 24 схватки ведущих борцов республики, в том числе финальные части соревнований (борьба за первые и третьи места). Анализ технико-тактических действий проведен путем видеозаписей, размещенных на различных интернет-сайтах. При анализе технико-тактических действий мы использовали таблицы, предложенные К.С. Колодезниковым и В.В. Ефремовым[4,5].

\section{РЕЗУЛЬТАТЫ И ОБСУЖДЕНИЕ}

В результате проведенных исследований нами была составлена общая характеристика и проведен анализ результативности соревновательной деятельности борцов вольного стиля, входящих в состав сборной команды Республики Саха (Якутия), на официальных соревнованиях (таблица 1).

Таблица 1 - Анализ результативности соревновательной деятельности сборной Республики Саха (Якутия)

\begin{tabular}{|c|c|c|c|c|c|}
\hline $\begin{array}{c}\text { Технические действия/ } \\
\text { соревнования }\end{array}$ & ЧР-2016 & ЧР-2017 & Ярыгин-2016 & Всего & $\%$ \\
\hline $\begin{array}{c}\text { Партер: } \\
\text { 1. Перевороты накатом }\end{array}$ & 8 & 6 & 9 & 23 & 13,1 \\
\hline $\begin{array}{c}\text { 2. Перевороты обратным } \\
\text { поясом }\end{array}$ & 1 & 3 & 1 & 5 & 2,9 \\
\hline 3. Контратаки & 3 & 9 & 12 & 6,9 \\
\hline Всего в партере: & 12 & 18 & 2 & 40 & 22,9 \\
\hline Стойка: & 1 & 6 & 0 & 9 & 5,2 \\
\hline 4. Переводы & о & 9 & 3 & 0 & 0 \\
\hline 5. Броски & 4 & 9 & 16 & 9,1 \\
\hline
\end{tabular}




\begin{tabular}{|c|c|c|c|c|c|}
\hline 7. Проход в ноги & 31 & 37 & 12 & 80 & 45,7 \\
\hline 8. Контратаки & 13 & 4 & 11 & 28 & 16 \\
\hline $\begin{array}{c}\text { 9. Досрочно выигранные } \\
\text { схватки и туше }\end{array}$ & 0 & 0 & 2 & 2 & 1,1 \\
\hline $\begin{array}{c}\text { Всего в стойке: } \\
\text { Кол-во технических } \\
\text { действий }\end{array}$ & 49 & 56 & 30 & 135 & 77,1 \\
\hline
\end{tabular}

Обобщая результаты трёх соревнований, технических действий (5,2\%); выталкивания за можно констатировать тот факт, что из 24 ковёр - 16 выполненных технических действий анализируемых схваток технических действий (9,1\%); проход в ноги - 80 (45,7\%); контратаки в стойке было отмечено 135 приемов $(77,1 \%), \quad$ - 28 (16\%). В партере спортсменами наиболее а в партере - 40 приемов (22,9\%). Анализ часто использовались перевороты накатом технических действий, выполняемых борцами 23 выполненных технических действия (13,1\%), в стойке, на данных соревнованиях показал, что перевороты обратным поясом - 5 (2,9\%) и наиболее часто используемыми атакующими контратаки-12 $(6,9 \%)$ (таблица 1). действиямиявлялись:переводы-9выполненных

Таблица 2 - Показатели результативности действий

\begin{tabular}{|c|c|c|c|c|c|c|c|c|}
\hline \multirow{2}{*}{$\begin{array}{c}\text { Соревнования } \\
\text { / спортсмены }\end{array}$} & \multicolumn{2}{|c|}{ чР-2016 } & \multicolumn{2}{c|}{ ЧР-2017 } & \multicolumn{2}{c|}{ Ярыгин-2016 } & \multicolumn{2}{c|}{ Хср. } \\
\cline { 2 - 9 } & $\begin{array}{c}\text { За турнир } \\
\text { (в \%) }\end{array}$ & $\begin{array}{c}\text { За схватку } \\
\text { (в \%) }\end{array}$ & $\begin{array}{c}\text { 3а турнир } \\
\text { в (\%) }\end{array}$ & $\begin{array}{c}\text { 3а схватку } \\
\text { (в \%) }\end{array}$ & $\begin{array}{c}\text { 3а турнир } \\
\text { в (\%) }\end{array}$ & $\begin{array}{c}\text { 3а схватку } \\
\text { (в \%) }\end{array}$ & $\begin{array}{c}\text { 3а турнир } \\
\text { в (\%) }\end{array}$ & $\begin{array}{c}\text { 3а } \\
\text { схватку } \\
\text { (в \%) }\end{array}$ \\
\hline Борец-1 & 45 & 15 & 58,1 & 11,6 & 0 & 0 & 51,5 & 25,7 \\
\hline Борец-2 & 53 & 17,7 & 38,5 & 19,2 & 83,3 & 20,8 & 58,2 & 19,4 \\
\hline Борец-3 & 54,5 & 27,25 & 33,3 & 16,6 & 54,5 & 27,2 & 47,5 & 15,8 \\
\hline Хср. & 50,8 & 20 & 43,3 & 15,8 & 68,9 & 24 & 54,3 & 20 \\
\hline
\end{tabular}

Данные, представленные в таблице 2, позволили установить следующее: самый высокий показатель результативности (оцененных) действий у Борца-1 составил 58,1\% (ЧР-2017); у Борца-2 - 83,3\% (Ярыгин-2016); у Борца-3 - 54,5\% (ЧР-2016).

Путем анализа соревновательных технических действий установлено, что Борец-1 очень активно борется, эффективен как в атаке, так и в защите. У него много движений, часто проходит в ноги и берет баллы. Борец-2 предпочитает действовать тактически гибко, максимально собранно и с высокой надежностью защитных действий. Выполняет результативные действия, КПД составляет в среднем $58,2 \%$ - это самый лучший показатель. Нужно заметить, что Борец-3 показал лучшие результаты по защитным действиям и контратакам.

Просмотр выступления борцов вольного стиля на Чемпионате России 2016 г., Чемпионате России 2017 г. и на турнире И.С. Ярыгина позволяет сделать вывод, что каким бы ни был уровень технической подготовленности, каким бы эффективным приемов ни владел борец, без соответствующей тактической подготовки провести прием невозможно.

На основе анализа соревновательной деятельности был составлен тренировочный 
план подготовки борцов вольного стиля сборной

Республики Саха (Якутия) на 2017 год.

Таблица 3 - Тренировочный план подготовки борцов вольного стиля сборной Республики Саха (Якутия) 2017 год

\begin{tabular}{|c|c|c|c|c|c|c|c|c|c|c|c|}
\hline \multicolumn{3}{|c|}{ Период подготовка } & \multicolumn{9}{|c|}{ ПОДГОТОВИТЕЛЬНЫЙ ПЕРИОД } \\
\hline \multicolumn{3}{|c|}{ Этап подготовки } & \multicolumn{9}{|c|}{ Специально-подготовительный } \\
\hline \multirow{2}{*}{\multicolumn{3}{|c|}{$\begin{array}{l}\text { Месяц } \\
\text { Неделя }\end{array}$}} & \multicolumn{5}{|c|}{ Апрель } & \multicolumn{4}{|l|}{ Май } \\
\hline & & & $\mathbf{1}$ & \multirow{2}{*}{$\begin{array}{c}2 \\
\text { o3- }^{-} \\
09\end{array}$} & \multirow{2}{*}{$\begin{array}{l}3 \\
10- \\
16\end{array}$} & \multirow{2}{*}{$\begin{array}{l}4 \\
17^{-} \\
23\end{array}$} & \multirow{2}{*}{$\begin{array}{c}5 \\
24- \\
30\end{array}$} & \multirow{2}{*}{$\begin{array}{l}6 \\
1-7\end{array}$} & \multirow{2}{*}{$\begin{array}{l}7 \\
8-14\end{array}$} & \multirow{2}{*}{$\begin{array}{l}8 \\
15-21\end{array}$} & \multirow{2}{*}{$\begin{array}{l}9 \\
22- \\
28\end{array}$} \\
\hline № & День недели & Время & $\begin{array}{c}27^{-} \\
02 \\
\end{array}$ & & & & & & & & \\
\hline \multicolumn{3}{|c|}{ Мезоциклы } & & & & & $\mathrm{COP}$ & \multicolumn{2}{|l|}{ BT } & \multicolumn{2}{|r|}{ БР } \\
\hline \multicolumn{3}{|c|}{ Микроцикл } & ПДВ & $\mathrm{COP}$ & $\mathrm{BOC}$ & ПДВ & $\mathrm{COP}$ & BOC & ОРД & ОРД & ОРД \\
\hline \multirow{3}{*}{$\mathbf{1}$} & \multirow{3}{*}{ Понедельник } & утро & & 3ap & 3ар & 3ap & 3ар & 3ар & 3ap & Зар & 3ар \\
\hline & & день & & ВП & K & ССП & СТТП & СТТП & K & СФП & СФП \\
\hline & & вечер & & Инд & ВП & Инд & Инд & Инд & ВП & Кросс & ССП \\
\hline & & утро & & 3ap & 3ap & 3ap & 3ap & 3ap & 3ap & 3ap & 3ap \\
\hline 2 & Вторник & день & & ВП & Кросс & Инд & ТП & ТП & Кросс & ССП & ССП \\
\hline & & вечер & & Инд & ВП & СТТП & Инд & Инд & Игр & СТТП & СТТП \\
\hline & & утро & & 3ap & 3ap & 3ap & 3ap & 3ap & 3ap & $3 a p$ & 3ap \\
\hline 3 & Среда & день & & ВП & Игр & ТП & & & Плав & Игр & Игр \\
\hline & & вечер & & Инд & ВП & ВП & ВП & ВП & ВП & ВП & ВП \\
\hline & & утро & & 3ap & 3ap & 3ap & 3ap & 3ap & 3ар & Зар & 3ap \\
\hline 4 & Четверг & день & & ВП & Плав & СТТП & & & СФП & СТТП & СТTП \\
\hline & & вечер & & Инд & АП & Инд & Инд & Инд & АП & $\mathrm{CC \Pi}$ & $\mathrm{CC \Pi}$ \\
\hline & & утро & & 3ap & 3ap & 3ap & MT & ДВФО & 3ap & 3ap & 3ap \\
\hline 5 & Пятница & день & & ВП & Kросc & КС & MT & ДВФО & СФП & Плав & Плав \\
\hline & & вечер & & Инд & ТП & Инд & MT & ДВФО & ТП & АП & Инд \\
\hline & & утро & 3ap & MT & 3ap & 3ap & MT & ДВФО & 3ap & 3ap & 3ap \\
\hline 6 & Суббота & день & ВП & MT & Игр & Инд & MT & ДВФО & Игр & Игр & Игр \\
\hline & & вечер & Инд & MT & & ВП & MT & ДВФО & & & CTTI \\
\hline 7 & Воскресенье & день & ВП & MT & вП & вП & MT & дВФО & вП & ВП & ВП \\
\hline Kor & гр.и сорев. схва & и в (час). & & & 1 & 1 & & & 1 & 2 & 1 \\
\hline 3ap & гдка & & & 3 & 3 & 3 & 2 & 3 & 3 & 3 & 3 \\
\hline Атл & етическая подго & вкка & 4 & 2 & 2 & 3 & & 1 & 1 & 1 & 1 \\
\hline Kрс & ссовая подготов & & & 3 & 3 & 4 & & 1 & 1 & 1 & 1 \\
\hline Пл: & вание & & & 1 & 1 & 1 & & 1 & 1 & 1 & 1 \\
\hline Teo & етическая подг & овка & & & & 1 & 1 & 1 & 1 & 1 & 1 \\
\hline Игр & овая тренировк & & & 1 & 1 & 1 & 1 & 1 & 1 & 1 & 1 \\
\hline $\mathbf{C \Phi}$ & & & & 3 & 3 & 2 & & 2 & 3 & 3 & 3 \\
\hline $\begin{array}{l}\text { Ско } \\
\text { под }\end{array}$ & $\begin{array}{l}\text { остно-силовая } \\
\text { отовка }\end{array}$ & & & 1 & 1 & 3 & & 1 & 2 & 2 & 2 \\
\hline Ин & - работа с трене & & & 3 & 3 & 4 & 3 & 2 & 2 & 3 & 3 \\
\hline CTI & & & & 4 & 4 & 6 & 4 & 3 & 3 & 3 & 4 \\
\hline Me & ицинский конт| & & & 1 & 2 & 1 & & 2 & 2 & 1 & \\
\hline $\begin{array}{l}\text { Boc } \\
\text { IIpo }\end{array}$ & $\begin{array}{l}\text { тановительные } \\
\text { цедуры }\end{array}$ & & & & & 4 & & & & 4 & \\
\hline $\begin{array}{l}\text { Kor } \\
\text { Tec }\end{array}$ & $\begin{array}{l}\text { гроль (педагоги } \\
\text { ы) }\end{array}$ & ские & 2 & & 2 & & & 2 & & & 2 \\
\hline $\begin{array}{l}\text { Ко } \\
\text { дне }\end{array}$ & ичество тренир & очных & & 5 & 5 & 6 & 5 & 6 & 6 & 6 & 6 \\
\hline Ко & во тренировоч1 & х часов & & 22 & 26 & 34 & 11 & 20 & 21 & 26 & 23 \\
\hline Обг & ий объем часов & м месяц: & 93 & & & & & 90 & & & \\
\hline
\end{tabular}


В таблице 4 представлен тренировочный план подготовки борцов на соревновательном периоде.

Таблица 4 - Тренировочный план подготовки борцов вольного стиля сборной Республики Саха(Якутия) 2017 год

\begin{tabular}{|c|c|c|c|c|c|c|c|c|}
\hline \multirow{2}{*}{\multicolumn{4}{|c|}{$\begin{array}{l}\text { Период подготовка } \\
\text { Этап подготовки }\end{array}$}} & \multicolumn{5}{|c|}{ СОРЕВНОВАТЕЛЬНЫЙ ПЕРИОД } \\
\hline & & & & & \multicolumn{4}{|c|}{ 1-й соревновательный } \\
\hline \multicolumn{4}{|c|}{ Месяц } & \multicolumn{5}{|l|}{ Июнь } \\
\hline \multicolumn{4}{|c|}{ Неделя } & 10 & 11 & 12 & 13 & 14 \\
\hline \multicolumn{2}{|l|}{ № } & День недели & Время & 29-04 & $05-11$ & 12-18 & 19-25 & 26-02 \\
\hline \multicolumn{4}{|c|}{ Мезоциклы } & \multicolumn{2}{|l|}{ ПС } & COP & & \\
\hline \multicolumn{4}{|c|}{ Микроцикл } & УД & ПДВ & $\mathrm{COP}$ & $\mathrm{BOC}$ & $\mathrm{BOC}$ \\
\hline \multirow{3}{*}{$\mathbf{1}$} & \multirow{3}{*}{ Понедельник } & \multicolumn{2}{|l|}{ утро } & 3ap & 3 ap & 3ap & ЧР & \\
\hline & & \multicolumn{2}{|l|}{ день } & $\mathrm{CC \Pi}$ & СТTП & ВП & ЧР & \\
\hline & & \multicolumn{2}{|l|}{ вечер } & CTTI & KC & СТТП & ЧР & \\
\hline \multirow{3}{*}{2} & \multirow{3}{*}{ Вторник } & утро & & 3ap & 3ap & 3ap & & \\
\hline & & день & & Инд & СТТП & ВП & & \\
\hline & & вечер & & СТTाI & KC & Инд & & \\
\hline \multirow{3}{*}{3} & \multirow{3}{*}{ Среда } & утро & & 3ар & 3ap & ЧР & & \\
\hline & & день & & TII & ТП & ЧР & & \\
\hline & & вечер & & ВП & ВП & ЧР & & \\
\hline \multirow{3}{*}{4} & \multirow{3}{*}{ Четверг } & утро & & 3ар & 3ap & ЧР & & \\
\hline & & день & & Инд & & ЧР & & \\
\hline & & вечер & & СТTII & СТТП & ЧР & & \\
\hline \multirow{3}{*}{5} & & утро & & 3ар & 3ap & ЧР & & \\
\hline & Пятница & день & & $\mathrm{CC \Pi}$ & & ЧР & & \\
\hline & & вечер & & СТTा & СТТП & ЧР & & \\
\hline & & утро & & 3ар & 3ар & ЧР & & \\
\hline 6 & Суббота & день & & Игр & & ЧР & & \\
\hline & & вечер & & Инд & Инд & ЧР & & \\
\hline 7 & Воскресенье & день & & ВП & ВП & ЧР & ВП & ВП \\
\hline Kor & рев. схватки в (ч & c). & & 4 & & & & \\
\hline 3ap & & & & 3 & 3 & & & \\
\hline Атл & кая подготовка & & & & & & & \\
\hline Kpc & подготовка & & & & & & & \\
\hline Пл: & & & & & & & & \\
\hline Teo & ская подготовка & & & 1 & 3 & & & \\
\hline Игт & еенировка & & & 1 & & & & \\
\hline $\mathbf{C \Phi}$ & & & & & & & & \\
\hline Ско & -силовая подгот & вкка & & 3 & & & & \\
\hline Ин: & а с тренером & & & 4 & 3 & 1,5 & & \\
\hline CT1 & & & & 6 & 6 & 1,5 & & \\
\hline $\mathbf{M e}$ & кий контроль & & & 1 & 1 & & & \\
\hline Boc & ительные проце & ууры & & 4 & 4 & & & \\
\hline Kor & (педагогические & тесты) & & & & & & \\
\hline Ко & о тренировочнь & $\mathbf{x}$ дней & & 6 & 5 & 2 & & \\
\hline Кол & нировочных ча & & & 27 & 20 & 3 & 0 & 0 \\
\hline Обі & бем часов за мес & & & 50 & & & & \\
\hline
\end{tabular}

\section{ЗАКЛЮЧЕНИЕ}

Проделанные исследования позволили сделать следующие выводы:

1. Теоретический подготовка

высококвалифицированных борцов вольного стиля должна осуществляться в строгом соответствии с содержанием и структурой соревновательной деятельности. В последние годы соблюсти такое соответствие 
становится все сложнее, поскольку периодические изменения правил судейства и регламента проведения соревнований приводят к труднопредсказуемым последствиям и далеко не всегда имеют положительный эффект. Это заставляет борцов и тренеров находиться в постоянном поиске таких средств и методов подготовки, которые гарантируют рациональное приспособление учебнотренировочного процесса к изменениям условий соревновательнойдеятельности,внезависимости от их направленности. Для того чтобы объективно выявить направленность и величину изменений параметров технико-тактической подготовленности борцов, необходимо регулярно осуществлять стенографирование и видеозапись их соревновательных поединков на всех соревнованиях. Последующий анализ этой исходной информации позволяет системно представить содержание и структуру соревновательной деятельности каждого борца, выявив относительно сильные и слабые аспекты мастерства.
2.
$\mathrm{Ha}$
основе
анализа

соревновательной деятельности на Чемпионате России 2016 г., Чемпионате России 2017 г. и на международном турнире Голден Гран-При И.С. Ярыгина 2016 г. определен состав ТТД, применяемых борцами высшей квалификации. Дан анализ выполнения тех или иных ТТД борцами различных стилей ведения поединка; что позволяет корректировать методику и средства тренировки. Определено, что наибольшую информативность при оценке технико-тактических возможностей высококвалифицированных борцов несет в себе финальная часть соревнований, которая определяется результативностью, эффективностью, технической оснащенностью.

3. Проведено исследование, позволяющее констатировать, что борцы высокой квалификации владеют высокой технико-тактической подготовленностью. В экспериментальной работе нами изучены и проанализированы выступления трех ведущих борцов вольногостиля Республики Саха (Якутия), мастеров спорта Российской Федерации и мастеров спорта международного класса. Объектом наблюдения были соревнования по вольной борьбе: Чемпионат России 2016 г. (Якутск), Чемпионат России 2017 г. (Назрань), международный турнир Голден Гран-При им. И.С. Ярыгина 2016 г. (Красноярск).

Обобщая результаты трёх соревнований, можно констатировать тот факт, что из 24 анализируемых схваток технических действий в стойке было отмечено 135 приемов (77,1\%), а в партере - 40 приемов (22,9\%). Анализ технических действий, выполняемых борцами в стойке, на данных соревнованиях показал, что наиболее часто используемыми атакующими действиями являлись переводы - 9 выполненных технических действия (5,2\%); выталкивания за ковёр - 16 выполненных технических действий (9,1\%); проход в ноги - 80 (45,7\%); контратаки - 28 (16\%). В партере спортсменами наиболее часто использовались перевороты накатом 23 выполненных технических действия (13,1\%), перевороты обратным поясом - $5(2,9 \%)$ и контратаки - 12 (6,9\%).

Просмотр выступлений борцов вольного стиля на Чемпионате России 2016 г., Чемпионате России 2017 г. и на турнире И.С. Ярыгина позволяет сделать вывод, что каким бы ни был уровень технической подготовленности, каким бы эффективным приемов ни владел борец, без соответствующей тактической подготовки провести прием невозможно.

На основе анализа соревновательной деятельности составлен тренировочный план подготовки борцов вольного стиля сборной Республики Саха (Якутия) на 2017 год.

Исследовательская работа убедила нас в том, что применение анализа соревновательной деятельности тренерами и спортсменами способствует росту спортивного мастерства и результативности.

Данный опыт можно рекомендовать для использования всем ведущим тренерам и спортсменам.

\section{СПИСОК ЛИТЕРАТУРЫ}

1. Миндиашвили Д.Г., Завьялов А.И. Учебник тренера по борьбе. Красноярск: изд-во КПГУ. 2005: 376. 
2. Подливаев Б.А., Уваров В.П., Рожин Н.Н. Организационно-методические основы подготовки высококвалифицированных борцјов. Якутск. 2002: 90.

3. Туманян Г.С. Спортивная борьба: теория, методика, организация тренировки. Учебное пособие. В 4-х кн. Кн. IV. Планирование и контроль. М.: Советский спорт. 2000: 384.

4. Ефремов В.В., Колодезникова М.Г., Николаев Н.Д. Анализ соревновательной деятельности борцов вольного стиля высокой квалификации. Теория и практика физической культуры. 2017; 11: 66-68. П.И., Васильев Е.В. Мониторинг соревновательной деятельности боксера высокой квалификации. Теория и практика физической культуры. 2019; 10: 87-88.

6. Кузнецов А.С., Новаковский C.В., Соломахин О.Б. О целесообразности параллельного изучения атаки и защиты в греко-римской борьбе на этапе начальной подготовки. Педагогико-психологические и медико-биологические проблемы физической культуры и спорта. 2018; 13(1): 16-26. DOI: 10/14526/o1_2018_279

7. Brown D.B., Mackenzie J.E., Dennis K.K., Cullen R.W. Comparison of body composition technique to determine body fat in high school wrestlers. Journal of Exercise Physiologyonline. 2006; 9: 24-32.

8. Hubner-Wozniak E., Kosmol A., Lutoslawska G., Bem E.Z. Anaerobic performance of arms and legs in male and female freestyle wrestlers. Journal of Science and Medicine in Sport. 2004; 7: 473-480.

9. McGuigan M.R., Winchester J.B., Erickson T. The importance of isometric maximum strength in college wrestlers. Journal of Sports Science and Medicine. 2006; 5(CSSI): 108-113.

\section{Статья поступияа в редакцию: 09.11.2020}

Колодезникова Маргарита Герасимовна - кандидат педагогических наук, профессор, Северо-Восточный федеральный университет имени М.К. Аммосова, 677ооо, Республика Саха (Якутия), г. Якутск, ул. Белинского, дом 58, e-mail: mgkolod@inbox.ru

Колодезников Кирсан Степанович - кандидат педагогических наук, доцент, СевероВосточный федеральный университет имени М.К. Аммосова, 677ооо, Республика Саха (Якутия), 2. Якутск, ул. Белинского, дом 58, e-mail:kkirsan@mail.ru

Сидоров Павел Иванович - магистрант, Северо-Восточный федеральный университет имени М.К. Аммосова, 677ооо, Республика Саха (Якутия), г. Якутск, ул. Белинского, дом 58, e-mail: sportedin@mail.ru 